\title{
Inter-relationship of plasma markers of oxidative stress and thyroid hormones in schizophrenics
}

\author{
Moses $O$ Akiibinu ${ }^{1,2^{*}}$, Omobola A Ogundahunsi ${ }^{1}$ and Ebenezer $O$ Ogunyemi ${ }^{1}$
}

\begin{abstract}
Background: The relationship of oxidative stress to thyroid hormones has not been studied in the schizophrenics. The present study determined the status and interrelationship of plasma markers of oxidative stress, nitric oxide and thyroid hormones in thirty (17 males and 13 females) newly diagnosed patients with acute schizophrenia before initiation of chemotherapy. Twenty five (13 males and 12 females) mentally healthy individuals served as controls. Patients and controls with history of hard drugs (including alcohol and cigarette), pre-diagnosis medications (e.g. antiparkinsonian/antipsychotic drugs), chronic infections, liver disease and diabetes mellitus were excluded from the study. Plasma levels of total antioxidant potential (TAP), total plasma peroxides (TPP), nitric oxide (NO), malondialdehyde (MDA), thyroxine (T4), tri-iodothyronine (T3) and thyroid stimulating hormone (TSH) were determined in all participants using spectrophotometric and enzyme linked immunosorbent assay (ELISA) methods respectively. Oxidative stress index (OSI) was calculated as the percent ratio of total plasma peroxides and total antioxidant potential.
\end{abstract}

Findings: Significantly higher plasma levels of MDA ( $p<0.01)$, TPP ( $p<0.01)$, OSI $(p<0.01)$, T3 $(p<0.01)$ and T4 $(p<0.05)$ were observed in schizophrenics when compared with the controls. The mean levels of TAP, NO and TSH were significantly lower in schizophrenics $(p<0.01)$ when compared with the controls. The result shows that T3 values correlate significantly with MDA $(p<0.05)$ and TPP $(p<0.01)$ in schizophrenics.

Conclusions: Higher level of TPP may enhance thyroid hormogenesis in schizophrenics. Adjuvant antioxidant therapy may be a novel approach in the treatment of schizophrenic patients.

Keywords: Oxidative stress, Thyroid hormones, Schizophrenia

\section{Introduction}

Schizophrenia is a disorder of aberrant neurodevelopment with minor physical anomalies, neurological soft signs, and abnormalities of brain structure and function [1]. The brain abnormalities therefore cause deficits in both working memory and long term memory tasks [2]. It is marked by disturbances in thinking, emotional reaction, social behavior, with illusions and hallucination [3]. Proposed factors leading to schizophrenia include maternal exposure to stress (prenatal environmental insults), infection and/or immune activation, nutritional deficiencies, obstetric complications [4] and use of cannabis [5]. Changes in dopamine neurotransmission in schizophrenia have been related to hallucinations and

\footnotetext{
* Correspondence: akiibinumoses@yahoo.com

'Department of Chemical Pathology and Immunology, College of Health

Sciences, Olabisi Onabanjo University, Ago-Iwoye, Ogun State, Nigeria

Full list of author information is available at the end of the article
}

delusions in the patients. Effective therapy which blocks the dopamine system resolves these two clinical conditions [6].

Nitric oxide (NO) is a molecule formed in the cells through the conversion of the amino acid, L-arginine to NO by the action of nitric oxide synthase (NOs) [7]. NO participates in other biological processes such as vasodilatation, bronchodialation, inhibition of phagocyte, platelets aggregation, regulation of blood pressure, and defense against invading pathogens $[8,9]$. The synergistic effects of impaired synthesis, exhaustion of NO during anti-oxidative activities and diversion of the NO to the peroxynitrite (ONOO) pathway could contribute to its deregulated levels in certain disease conditions [10-12]. The vital roles played by NO in neurotransmission and maintenance of memory make it an interesting target molecule for schizophrenia research.
C Biomed Central

(c) 2012 Akiibinu et al; licensee BioMed Central Ltd. This is an open access article distributed under the terms of the Creative Commons Attribution License (http://creativecommons.org/licenses/by/2.0), which permits unrestricted use, distribution, and reproduction in any medium, provided the original work is properly cited. 
Hydrogen peroxide, a pro-oxidant generated at physiological level in the apical pole of the thyroid cells is required by normal thyroid gland to oxidize iodide into iodine in a reaction catalyzed by thyroperoxidase [13-15]. Other reactions catalyzed in thyroid hormogenesis include the coupling of mono-iodotyrosine and diiodotyrosine, and in the synthesis of reverse T3 [16]. Chittiprol et al [17] reported significantly higher level of oxidative stress and lipid peroxidation which decline with treatment in schizophrenic patients. Yazici et al [18] also reported significantly higher levels of thyroid hormones in schizophrenia. None of the previous researchers related the abnormal patterns of thyroid hormones in schizophrenics to excessive free radical generation. Since hydrogen peroxide catalyses a series of chemical reactions in the synthesis of thyroid hormones, it may be possible to have free radical induced hyperthyroidism in schizophrenia. This study was designed to probe further in schizophrenic research, and bridge other gaps by determining the levels of thyroid hormones and makers of oxidative stress in schizophrenics.

\section{Materials and methods Materials}

Thirty (17 males and 13 females) newly diagnosed patients with acute schizophrenia (duration- between 2.5 and 4.0 months), attending Psychiatric Hospital Abeokuta, Nigeria and Psychiatric Hospital Yaba, Lagos, Nigeria were recruited for this study before initiation of chemotherapy. The patients were traders and middle class civil servants. Informed consent was obtained from their relations before being included in this study. The patients were residents of Ogun and Lagos states in Nigeria. DSM-IV diagnosis of schizophrenia was established by the consultant psychiatrist in charge of the schizophrenic patients, using the Assessment of Positive and Negative Syndrome Scale (PANSS) [19]. The schizophrenic patients were either receiving spiritual treatment or not under specific treatment before being recruited for this study. Those patients with history of hard drugs (including alcohol and cigarette), pre-diagnosis medications (e.g. antiparkinsonian/antipsychotic drugs), chronic infections, liver disease and diabetes mellitus were excluded from this study. Twenty five (13 males and 12 females) apparently healthy staff of Olabisi Onabanjo University Teaching Hospital, Shagamu, Ogun state, Nigeria, served as controls. None of the controls was on any medication (including alcohol, cigarette and multivitamins), had history of chronic infections, malnutrition syndrome, depression, psychosis or metabolic dysfunction (such as diabetes mellitus, liver diseases, cancer) that could interfere with their oxidative metabolites and thyroid hormone status. The experimental protocol was approved by the Research Ethical Committee of Psychiatric Hospital Abeokuta, Nigeria.

$5 \mathrm{ml}$ of venous blood sample was taken from the anticubital vein of each participant. The sample in lithium heparin bottle was centrifuged within one hour of collection, after which the plasma was separated and stored at $-70^{\circ} \mathrm{C}$ until assayed.

\section{Methods}

T4, T3 and TSH were determined by using commercially prepared enzyme linked immunosorbent assay (ELISA) reagents (cat. numbers Z01208, Z01232 and Z01237 respectively) by Dialab, Gesellschaft, Vienna, as described by Young et al [20]. The MDA, a product of lipid peroxidation was determined by using the method of Varshney and Kale [21]. TAP was determined using the ferric reducing/antioxidant power (FRAP) assay $[22,23]$. Method of Harma et al [23] was used for the determination of TPP. The OSI, an indicator of the degree of oxidative stress was determined as the percent ratio of the total plasma peroxide $\left(\mu \mathrm{Mol} \mathrm{H}_{2} \mathrm{O}_{2} / \mathrm{L}\right)$ to the total antioxidant activity ( $\mu$ mol.Trolox equiv./L) [23]. NO was determined using the method described by Wanchu et al [24].

\section{Statistical analysis}

Data processing and statistics were done using SPSS version 10. The data were expressed as Mean \pm SD. Student $(\mathrm{t})$ test was used for comparison of schizophrenics and controls. Pearsonian correlation coefficient (r) was calculated. The changes were considered significant, when p-values were less than 0.05 .

\section{Findings}

Age and gender distributions in the schizophrenics and controls were expressed in Table 1. The schizophrenics and the controls were age and sex matched. The results of this study indicate significantly $(\mathrm{p}<0.01)$ increased plasma levels of TPP, OSI and MDA in schizophrenics when compared with the controls. Meanwhile, the plasma levels of NO and TAP decreased significantly ( $p$ $<0.01)$ in schizophrenia when compared with the controls (Table 2). This is an indication of oxidative stress

\section{Table 1 Physical Characteristics of Schizophrenics and} Controls

\begin{tabular}{lcc}
\hline Characteristics & Schizophrenics $(\mathbf{N}=\mathbf{3 0})$ & Controls $(\mathbf{N}=\mathbf{2 5})$ \\
\hline Age (years) & $25-43$ & $22-45$ \\
Gender: & & \\
Male $(\mathrm{n})$ & 17 & 13 \\
Females $(\mathrm{n})$ & 13 & 12. \\
\hline
\end{tabular}

$\mathrm{N}=$ total number of subjects used for the study

$\mathrm{n}=$ gender number in the study 
Table 2 Markers of Oxidative Stress in Schizophrenics and Controls

\begin{tabular}{lccc}
\hline & Schizophrenics & Controls & p values \\
\hline MDA $(\mathrm{nMol} / \mathrm{ml})$ & $9.5 \pm 3.0$ & $6.5 \pm 1.9$ & $<0.01^{*}$ \\
TPP $\left(\mu \mathrm{Mol} \mathrm{H} \mathrm{H}_{2} / \mathrm{L}\right)$ & $16.5 \pm 1.2$ & $10.1 \pm 0.5$ & $<0.01^{*}$ \\
TAP $(\mu \mathrm{Mol}$ Trolox equiv./L) & $975 \pm 140$ & $1300 \pm 196$ & $<0.01^{*}$ \\
OSI $(\%)$ & $1.7 \pm 0.8$ & $0.8 \pm 0.3$ & $<0.01^{*}$ \\
NO $(\mu \mathrm{Mol} / \mathrm{L})$ & $17.8 \pm 6.4$ & $24.7 \pm 5.5$ & $<0.01^{*}$ \\
$\mathrm{~N}$ & 30 & 25. & \\
\hline
\end{tabular}

MDA = malondialdehyde. OSI = oxidative stress index

TPP total plasma peroxides. $\mathrm{NO}=$ nitric oxide

TAP = total antioxidant potential. $\mathrm{N}=$ number of subjects used in the study

* = significantly different from controls

in the schizophrenics. The plasma levels of T3 and T4 (Table 3) increased significantly ( $\mathrm{p}<0.01$ and $\mathrm{p}<0.05$ respectively) while the mean value of TSH was significantly lower $(p<0.01)$ in the schizophrenic patients when compared with the controls. There were positive correlations observed between T3 and MDA $(\mathrm{p}<\mathbf{0 . 0 5})$ and between T3 and TPP ( $<<\mathbf{0 . 0 1})$ in the schizophrenics (Tables 4 and 5 respectively), showing strong association between oxidative stress and T3 synthesis.

\section{Discussion}

Hydrogen peroxide has been identified as an important factor in thyroid hormogenesis by the previous researchers. Overproduction of this pro-oxidant/free radical has also been implicated in the pathogenesis of many disease conditions. Several reports showed that sources of free radicals in schizophrenics include auto-oxidation of cathecholamines, the trauma, post traumatic stress disorder, high neuronal activity, increased oxygen consumption during high neuronal activity [25], several chronic medical illnesses [26], somatic symptoms [27], malnutrition, endocrine disorder and infections [4]. Oxidative stress results when there is increased free radical generation beyond the detoxification capacity of the antioxidant defense system [28]. The possible causes of free radical generation in our schizophrenic patients could be malnutrition, high neuronal activity; chronic infections and trauma (in abandoned or roughly handled patients). Our results agree with previous researchers

Table 3 Thyroid Hormones Levels in Schizophrenics and Controls

\begin{tabular}{lccc}
\hline & Schizophrenics & Controls & p -values \\
\hline T3 $(\mathrm{ng} / \mathrm{ml})$ & $7.5 \pm 1.5$ & $1.4 \pm 0.5$ & $<0.01^{*}$ \\
$\mathrm{~T} 4(\mathrm{nmol} / \mathrm{L})$ & $65.0 \pm 18.9$ & $50.4 \pm 12.7$ & $<0.05^{*}$ \\
$\mathrm{TSH}(\mathrm{miU} / \mathrm{L})$ & $0.25 \pm 0.2$ & $1.4 \pm 0.5$ & $<0.01^{*}$ \\
$\mathrm{~N}$ & 30 & 25. & \\
\hline
\end{tabular}

$\mathrm{T} 3$ = tri-iodothyronine $\mathrm{TSH}=$ thyroid stimulating hormone $\mathrm{T} 4=$ thyroxine

$\mathrm{N}=$ number of subjects used in the study.

* = significantly different from controls
Table 4 Correlation between MDA and thyroid hormones in schizophrenics ( $\mathbf{N}=\mathbf{3 0}$ )

\begin{tabular}{lll}
\hline Group & Correlation coefficient $(\mathbf{r})$ & $\mathbf{p}$-values \\
\hline MDA-T3 & $\mathbf{0 . 5 1}$ & $<0.05^{*}$ \\
MDA-T4 & 0.3 & 0.4 \\
MDA-TSH & 0.36 & 0.2. \\
\hline
\end{tabular}

* = significantly different from controls

$\mathrm{N}=$ number of subjects used in the study

[29] who reported excessive free radical generation, lipid peroxidation and oxidative stress in schizophrenics. Evidences from previous researchers also indicate increased plasma lipid peroxidation and decreased levels of essential fatty acids in the brains of the schizophrenic patients $[30,31]$.

Total antioxidants potential (TAP) is an index of all classes of antioxidants. Increased demand in the detoxification/neutralization process of free radicals or micronutrient deficiency (malnutrition) may be responsible for the lower levels of antioxidants in the schizophrenics [28]. This increased utilization of antioxidants demonstrated in schizophrenics leads to depressed plasma levels and reduced urinary excretion of ascorbic acid after an ascorbic acid load [32,33]. Our findings agree with a number of reports which indicate significantly lower level of total antioxidant in schizophrenics. Dadheech et al [28] reported significantly lower levels of superoxide dismutase and glutathione peroxidase in schizophrenic patients. In a study by Raffa et al [29], significantly lower levels of superoxide dismutase and catalase were also reported in schizophrenic patients. In their study, the antioxidant deficiency was associated with oxidative stress and malnutrition. This oxidative stress has also been associated with the aging process and chronic stage of the illness in some schizophrenics investigated by Dadheech et al [28].

The ameliorative effects of antioxidant vitamins $\mathrm{C}$ and $\mathrm{E}$ in some Wistar rats with ischemic brain injury confirmed the deteriorative effect of the oxidative stress in the brain [17]. In another study, decreased plasma level of the cell membrane antioxidant, $\alpha$-tocopherol was associated with increased oxidative stress in schizophrenics [34]. An increased plasma level of histamine is a factor in the behavioral defect commonly observed in

Table 5 Correlation between TPP and thyroid hormones in schizophrenics $(\mathrm{N}=\mathbf{3 0})$

\begin{tabular}{lll}
\hline Group & Correlation coefficient $(\mathbf{r})$ & p-values \\
\hline TPP-T3 & 0.8 & $<0.01^{*}$ \\
TPP-T4 & 0.46 & 0.15 \\
TPP-TSH & 0.41 & 0.09. \\
\hline
\end{tabular}

* = significantly different from controls

$\mathrm{N}=$ number of subjects used in the study 
schizophrenia [35]. In-vitro studies showed that vitamin $\mathrm{C}$ reduces histamine levels by promoting the formation of a mono-oxygenated form of $\mathrm{N}$-acetylhistamine [36]. But contrary to these opinions, Straw et al [37] reported that there was neither a change in psychopathology of schizophrenic patients nor was there any apparent pharmacokinetic interaction with haloperidol after ascorbic load.

Nitric oxide is produced in the endothelia of the blood vessels from the amino acid, L-arginine by the enzymatic reaction with oxygen catalyzed by nitric oxide synthase, in the presence of NADPH, tetrahydrobiopterin and flavin adenine nucleotides as co-factors. The highest concentration of $\mathrm{NO}$ is found in the brain for the purpose of cell migration, formation of synapses, receptor mediated neurotransmission, cognitive abilities [38], maintenance of memory, and for regulation of blood pressure [7]. Brain NO is involved in various processes such as immunological responses, neuroplasticity, neurodevelopment and neurotransmitter release. The reaction between peroxides and $\mathrm{NO}$ in a pathway leads to the production of peroxy-nitrite $[11,12,16,39]$. Peroxy-nitrite has greater ability to diffuse away from the site of production and can induce more selective and ultimately harmful oxidative damage such as the initiation of lipid peroxidation $[40,41]$. Several research findings, ranging from genetic and post mortem to neurochemical and psychopharmacological evidence support an involvement of the NO-signaling system in schizophrenia pathophysiology. There have been conflicting reports on the levels of NO in schizophrenia: some of them suggesting an increase of the NOmediated neurotransmission, and another part supporting a decrease [42]. Contrary to the report of Zoroglu et al [43] who demonstrated significantly higher level of $\mathrm{NO}$ and adrenomedullin in schizophrenia, our result shows significantly lower level of NO in acute schizophrenia. Diversion of the nitric oxide to the peroxynitrite pathway mediated by high level of peroxides (i.e. TPP) could cause the lower plasma level of NO in our schizophrenic patients. Since L-arginine is the precursor of $\mathrm{NO}$, inadequate intake of L-arginine (malnutrition) could also cause impaired synthesis and lower level of NO in these schizophrenic patients. This finding therefore calls for further studies to establish the levels of peroxy-nitrite and NO in the brain and plasma of schizophrenic patients.

To the knowledge of the authors, this study is the first to relate the plasma markers of oxidative stress with thyroid hormogenesis in schizophrenics. In the synthesis of thyroid hormones, hydrogen peroxide is required by the thyroid cells to oxidize iodide into iodine in a reaction catalyzed by thyroperoxidase [13-15] and also in the coupling of mono-iodotyrosine and di-iodotyrosine, and synthesis of reverse T3 [16]. The fact that higher levels of total plasma peroxides and MDA correlate with T3 in schizophrenics is the novel of this study. Our result agrees with the reports of the previous researchers [44] that significantly higher levels of free T3 and free T4 are features of schizophrenia. Yazici et al [18] also reported significantly higher levels of total T3 and free T3 in schizophrenics when compared with the controls. Baumgartner et al [45] also observed abnormal T4 level in acute schizophrenic patients, but the serum level declined in treated schizophrenic patients when compared with the control.

In conclusion, oxidative stress in schizophrenics may enhance thyroid hormone synthesis. Therefore, adjuvant antioxidant therapy may be a novel approach in the treatment of schizophrenic patients to avert the consequences of oxidative stress.

\section{Limitations of the study}

Non-compliance of relations of many patients and limited numbers of acute cases of schizophrenia without pre-diagnosis medications contributed to the small sample size.

\section{Acknowledgements}

This study is the continuation of the studies by Chittiprols et al [17] who reported oxidative stress in schizophrenics and Yazici et al [18] who also reported higher levels of thyroid hormones in schizophrenics.

\section{Author details}

${ }^{1}$ Department of Chemical Pathology and Immunology, College of Health Sciences, Olabisi Onabanjo University, Ago-Iwoye, Ogun State, Nigeria. ${ }^{2}$ G.P.O Box 11379 Dugbe, Ibadan, Oyo State, Nigeria.

\section{Authors' contributions}

$\mathrm{AMO}, \mathrm{OAO}$ and EOO designed the research, AMO did the analysis and all authors contributed and approved the final manuscript.

\section{Competing interests}

The authors declare that they have no competing interests.

Received: 18 August 2011 Accepted: 31 March 2012

Published: 31 March 2012

\section{References}

1. John JP: Fronto - temporal dysfunction in schizophrenia, a selective review. Indian J Psychiatr 2009, 51:180-190.

2. Van Snellenberg JX: Working memory and long term memory deficits in schizophrenia; is there a common substrate? Psychiatry Res 2009, 174:89-96.

3. Horrobin D: In The lipid hypothesis of schizophrenic in brain lipids and disorders in biological psychiatry. Volume 35. Edited by: Skinner ER. Amsterdam: Elsevier Science; 2002:39-52.

4. Meyer U, Feldon J: Epidemiology driven neuro-developmental animal models of schizophrenia. Prog Neurobiol 2009.

5. LeBee PY, Fatseas M, Denis C, Lavic E, Auriacombe M: Cannabis and psychosis; search of a causal link through a critical and systematic review. Encéphale 2009, 35:377-385.

6. Van Os J, Kapur S: Schizophrenia. Lancet 2009, 374:635-645

7. Jeffrey M, Ryder SJ, Martin S, Hawkins SAC, Terry L, Berthelin-Baker C, Bellworthy SJ: Oral inoculation of sheep with the agent of bovine spongiform encephalopathy (BSE). I. Onset and distribution of disease- 
specific PrP accumulation in brain and viscera. J Comp Pathol 2001, 124:280-289

8. Joshi AS, Li XC, Nimrod AC, EISohly HN, Walker LA, Clark AM: Dihydrochalcones from Piper longicaudatum. Planta Med 2001, 67:186-188.

9. Moncada S, Palmer RMJ, Higgs EA: Nitric oxide physiology, pathophysiology, and pharmacology. Pharmacol Rev 1991, 43:109-142.

10. Gaston B, Drazen JM, Loscalzo J, Stanler JS: The biology of nitrogen oxides in the airways. Am J Respir Crit Care Med 1994, 149:538-551.

11. Hogg N, Kalyanaraman B, Joseph J, Struck A, Parthasarthy S: Inhibition of low-density lipoprotein oxidation by nitric oxide. FEBS Lett 1993, 334:170-174.

12. Beckman JS, Ye YZ, Anderson PG, Chen J, Accavitti MA, Tarpey MM, White CR: Extensive nitration of protein tyrosine in human atheroscerosis detected by immunohistochemistry. Biol Chem Hoppe Seyler 1994, 375:81-88

13. Dai G, Levy O, Carrasco N: Cloning and characterization of the thyroid iodide transporter. Nature 1996, 379:458-460.

14. De Deken X, Wang D, Dumont JE, Miot F: Characterization of ThOX proteins as components of the thyroid $\mathrm{H} 2 \mathrm{O} 2$-generating system. Exp Cell Res 2002, 273:187-196.

15. Schweizer U, Chiu J, Kohrle J: Peroxides and peroxide-degrading enzymes in the thyroid. Antioxid Redox Signal 2008, 10:1577-1592.

16. Taurog A: Thyroid peroxidase and thyroxine biosynthesis. Recent Prog Horm Res 1970, 26:189-247.

17. Chittiprols VG, Neelakantachar N, Babu SV, Reddy NA, Shetty KT, Gangadhar BN: Oxidative stress and neopterin abnormalities in Schizophrenia, A longitudinal study. J Psychiatr Res 2009.

18. Yazici $K$, Yazici AE, Taneli B: Different neuro-endocrine profiles of remitted and non-remitted schizophrenic patients. Prog Neuropsychopharmacol Biol Psychiatry 2002, 26:579-584.

19. Kendell $R$, Jablensky A: Distinguishing between the validity and utility of psychiatric diagnoses. Am J Psychiatry 2003, 160:4-12.

20. Young DS, Pestaner LC, Gilberman U: Effects of drugs on clinical laboratory tests. Clin Chem 1975, 21:3660.

21. Varshney R, Kale RK: Effect of calmodulin antagonist on radiation-induced lipid peroxidation in microsomes. Int I Radiat Biol 1990, 58:733-743.

22. Benzie IE, Strain JJ: The ferric reducing ability of plasma (FRAP) as a measure of antioxidant power (the FRAP assay). Anal Biochem 1996, 239:70-76.

23. Harma M, Harma M, Enel O: Increased oxidative stress in patients with hydatidiform mole. Swiss Med Wkly 2003, 133:563-566.

24. Wanchu A, Khullar M, Bhatnagar A, Sud A, Bambery P, Singh S: Pentoxiphylline Reduces Nitric Oxide Production among Patients with HIV Infection. Immunol Lett 2000, 74:121-125.

25. Lommen MJ, Restifo K: Trauma and post traumatic stress disorder (PTSD) in patients with schizophrenia or schizoaffective disorder. Community Ment Health J 2009, S3:24.

26. Kozumplik O, Uzum S, Jakovljevic M: Psychotic disorders and Comorbidity somatic illness VS side effect. Psychiatr Danub 2009, 21:361-367.

27. Tschoner A, Flexishhacker FWW, Ebenbichler CF: Experimental antipsycholtics and metabolic adverse effects - findings from clinical trials. Curr Opin Investig Drugs 2009, 10:1041-1048.

28. Dadheech G, Mishra S, Gautam S, Sharma P: Evaluation of antioxidant deficit in schizophrenia. Indian J Psychiatr 2008, 50:16-20.

29. Andreazza AC, Kauer-Sant' Anna M, Frey BN, Bond DJ, Kapezinski F, Young LT, Yatham LN: Oxidative stress markers in bipolar disorder; $A$ metanalysi. J Affect Disord 2008, 111:135-144.

30. Raffa M, Mechri A, Othman LB, Fendri C, Gaha L, Kerkeni A: Decreased glutathione levels and antioxidant enzyme activities in untreated and treated schizophrenic patients. Prog Neuropsychopharmacol Biol Psychiatry 2009, 33:1178-1183.

31. Berger GE, Sinesny S, Amminger GP: Bioactive lipids in schizophrenia. Int Rev Psychiatry 2006, 18:85-98.

32. Suboticanec K, Vitamin C: status in schizophrenia. Bibl Nutr Dieta 1986 38:173-181.

33. Dadheech G, Mishra S, Gautam S, Sharma P: Oxidative stress and ascorbic acid status in schizophrenics. SFRR-Indian Bull 2005, 4:23-25.

34. Dadheech G, Mishra S, Gautam S, Sharma P: Oxidative stress, atocopherol, ascorbic acid and reduced glutathione status in schizophrenics. Indian J Clin Biochem 2006, 21:34-38.
35. Whitford T: The underlying mechanisms of brain allergies. J Orthomol Med 2000, 15:5-14.

36. Uchida K, Mitsui M, Kawakishi S: Mono-oxygenation of N-acetylhistamine mediated by Lascorbate. Biochim Biophys Acta 1989, 991:377-379.

37. Straw GM, Bigelow LB, Kirch DG: Haloperidol and reduced haloperidol concentrations and psychiatric ratings in schizophrenic patients treated with ascorbic acid. J Clin Psychopharmacol 1989, 9:130-132.

38. Bernstein H, Bogerts B, Keilhoff G: The many faces of nitric oxide in schizophrenia. A Review. Schizophr Res 2005, 78:69-86.

39. Okouchi M, Ekshyyan O, Maracine M, Aw TY: Neuronal apoptosis in neurodegeneration. Antioxid Redox Signal 2007, 9:1060-1096.

40. Hogg N, Kalyanaraman B, Joseph J, Struck A, Parthasarthy S: Inhibition of low-density lipoprotein oxidation by nitric oxide. FEBS Lett 1993, 334:170-174

41. Beckman JS, Ye YZ, Anderson PG, Chen J, Accavitti MA, Tarpey MM, White CR: Extensive nitration of protein tyrosine in human atheroscerosis detected by immunohistochemistry. Biol Chem Hoppe Seyler 1994, 375:81-88

42. Oliveira JP, Zuardi AW, Hallak JE: Role of Nitric Oxide in Patients with Schizophrenia- a Systematic Review of the Literature. Curr Psychiatr Rev 2008, 4:219-227.

43. Zoroglu SS, Herken H, Yürekli M, Uz E, Tutkun H, Savaş HA, Bagci C, Ozen ME, Cengiz B, Cakmak EA, Dogru Ml, Akyol O: The possible pathophysiological role of plasma nitric oxide and adrenomedullin in schizophrenia. J Psychiatr Res 2002, 36:309-315.

44. Sim K, Chong SA, Chan YH, Lum NM: Thyroid dysfunction in chronic schizophrenia within a state psychiatric hospital. Ann Acad Med Singapore 2002, 1:641-644.

45. Baumgartner A, Pietzcker A, Gaebel W: The hypothalamic-Pituitary-thyroidaxis in patients with schizophrenia. Schizophr Res 2000, 44:23-24.

doi:10.1186/1756-0500-5-169

Cite this article as: Akiibinu et al:: Inter-relationship of plasma markers of oxidative stress and thyroid hormones in schizophrenics. BMC Research Notes 2012 5:169.

\section{Submit your next manuscript to BioMed Central and take full advantage of:}

- Convenient online submission

- Thorough peer review

- No space constraints or color figure charges

- Immediate publication on acceptance

- Inclusion in PubMed, CAS, Scopus and Google Scholar

- Research which is freely available for redistribution 